\title{
PENGENALAN KODE RESIN PLASTIK PADA SISWA MENENGAH ATAS UNTUK MEMBANGUN GENERASI PEDULI LINGKUNGAN
}

\author{
Sudirman ${ }^{1 *}$, Dina Asnawati ${ }^{1}$, Iwan Sumarlan ${ }^{1}$, Ganesh Darmayanti ${ }^{1}$, Siti Raudhatul Kamali ${ }^{1}$, Saprini \\ Hamdiani $^{1}$ \\ ${ }^{1}$ Program Studi Kimia, FMIPA Universitas Mataram \\ ${ }^{*}$ Co-Author :sudirman28@unram.ac.id
}

\begin{abstract}
ABSTRAK. Pegunaan dan penanganan sampah plastik sangat bergantung pada jenis plastiknya. Setiap plastik telah tercantum kode resin yang menunjukan jenis resin plastik tersebut serta bagaimana penggunaan dan penanganannya. Meski demikian, fakta di masyarakat belum mengenal kode resin tersebut. Sejumlah 91.42\% responden Siswa SMA Tegar Kelana mengaku tidak tahu tentang plastik. Selain itu, dari data diperoleh penangan sampah yang dilakukan oleh masyarakat disekitar sekolah khususnya sampah plastik masih lebih banyak dengan cara dibakar dan dibuang ketempat pembuangan begitu saja. Setelah dilakukan sosialisasi kode resin plastik pada siswa SMA Tegar Kelana Desa Suranadi, respon siswa sangat antusias. Sejumlah $98.04 \%$ respondent yang diuji telah berhasil dengan tepat memilah jenis plastik berdasarkan kode resinnya. Selain itu, hamper keseluruan responden menginginkan adanya kegiatan lebih lanjut.
\end{abstract}

Kata Kunci: Kode Resin Plastik, Generasi Peduli Lingkungan, Siswa Menengah Atas

ABSTRACT. The use and handling of plastic waste is very dependent on the type of plastic. Each plastic has a resin code that shows the type of plastic resin and how it is used and handled. However, the facts in the community are not familiar with the resin code. A total of $91.42 \%$ of respondents from Tegar Kelana High School students claimed not to know about plastic. In addition, from the data obtained by the community around the school handlers of garbage, especially plastic waste is still more by burning and disposed of in a place of disposal just like that. After the plastic resin code socialization was carried out on Tegar Kelana High School students in Suranadi Village, the students' responses were very enthusiastic. A total of $98.04 \%$ of the respondents tested succeeded in correctly sorting out the type of plastic based on the resin code. In addition, almost all respondents want further activities.

Keywords: Plastic Resin Code, Environmental Concerned Generation, Senior High Students

\section{PENDAHULUAN}

Pencemaran lingkungan oleh sampah plastik merupakan permasalahan yang tidak hanya terjadi di Indonesia, tetapi juga menjadi permasalahan global. Indonesia menduduki peringkat kedua setelah Tiongkok yang merupakan negera penyumbang sampah plastik ke lautan mencapai 0.481.29 juta metrik ton (J.R. Jambeck, 2015). Khususnya di Nusa Tenggara Barat hingga juni 2019, sebanyak 2.695-ton (80\%) sampah belum terurus dengan baik (Insidelombok, 2019). Penanganan sampah di NTB khususnya di Lombok masih menggunakan teknik konvensional, yaitu mengumpulkan sampah dari kota atau pemukiman warga untuk dibawa ke TPA (Tempat Pembuangan Akhir). Meskipun regulasi dalam penanggulan sampah terus diperbaiki, namun hal ini 
tidak bisa menyelesaikan permasalahan dalam penanggulan sampah secara permanen. Hal ini terbukti, hari demi hari gunungan sampah di TPA Regional Kebon Kongok terus menjulang tinggi dan menebarkan bau yang menyengat ke Desa sekitar TPA (Redaksi ACTNews , 2018).

Pencemaran oleh sampah plastik disebabkan oleh bebera factor. Pertama, sampah jenis plastik merupakan jenis sampah yang sangat sulit terurai secara alami. Plastik secara alami membutuhkan waktu 30 hingga 200 tahun (tergantung jenis plastiknya) untuk bisa terurai secara alami (Merino, et al., 2018). Hal ini disebabkan oleh Hanya jenis plastik polietilen (PE) dan polietilen tereftalat (PET) dengan kode RIN (resine identification number) 1 dan high density polyethylene (HDPE) dengan kode RIN 2 yang dapat di daur oleh industri (recycler). Sedangkan plastik dengan kode RIN 3-7 seperti PVC (polyvinyl chloride), LDPE (low density polyethylene), PP (polypropylene), PS (polystyrene) dan lainya tidak dapat didaur ulang sehingga digilongkan sebagai non-recycle plastic (NRP). Secara global diketahui hingga di tahun 2018, produksi plastik baru mencapai 9,1 juta ton produksi plastik baru dan terbuang sebagai sampah sebesar 6,9 juta ton. Selain itu diperkirakan tahun 2050 jika kondisi saat ini terus berlangsung, diperkirakan jumlah plastik yang tidak terdaur ulang mencapai 13,2 juta ton (LeChevet, dkk., 2018).

Faktor selanjutnya yang mempengaruhi tingginya tingkat pencemaran dan kurangnya pengelolaan plastik di Indonesia adalah biaya yang harus dikeluarkan dalam membangun industri daur ulang plastik yang efisien dan efektif sangatlah tinggi. Faktor lain yang tidak kalah penting selain kurangnya kesadaran masyarakat adalah pengetahuan akan plastik itu sendiri. Meskipun kesadaran masyarakat untuk membuang sampah pada tempatnya telah dilakukan dengan baik, tetap saja sampah plastik bukan sampah yang bisa diabaikan dan akan hilang dengan sendirinya.

Oleh karena itu, perlu dilakukan suatu pengenalan tetang simbol-simbol dan makna yang ada pada plastik tersebut sehingga masyarakat akan lebih dengan bijak menggunakan plastik bahkan lebih jauh, dengan pendampingan yang lebih itensif masyarakat dapat mengolahnya menjadi sesuatu yang bernilai ekonomi. Generasi muda saat ini yang dikenal sebagai generasi milenial, memiliki peranan penting dalam aspek kehidupan masyarakat. Sehingga generasi muda ini dapat dijadikan pelopor dalam meningkatkan pemahaman masyarkat akan penggunaan plastik.

Desa suranadi merupakan salah satu desa yang tidak jauh dari kota Mataram. Dimana desa ini juga memiliki berbagai tempat wisata yang ramai dikunjungi karena masih sangat asri. Meski demikian, pengelolaan sampah disana masih secara konvensional, dimana sampah tanpa dipilah dikumpulkan pada tempat pembuangan tanpa adanya tindak lanjut. Namun cepat atau lambat, semakin berkembang desa ini, makan tingkat pencemaran oleh limbah plastik tidak akan terelakan, dimana sampah plastik sangat sulit untuk terdegradasi secara alami yang nantinya dapat menyebabkan desa ini kehilangan kebersihannya sehingga berdampak pada lingkungan dan perekonomian masyrakat sekitar.

\section{ANALISIS PERMASALAHAN}

Dari uraian yang telah diulas pada bagian pendahuluan, terlihat bahwa permasalahan yang sangat mencolok khususnya di NTB adalah kurangnya pemahaman masyarakat tentang plastik itu sendiri. Mesikupun semua jenis plastik telah dicantumkan kode resin yang dapat dikenali untuk memilah dan memilih plastik berdasarkan jenis resinnya yang nantinya tujuannya untuk mempermudah penanganan plastik tersebut. Namun kenyataanya di masyarakat masih sangat minim pengetahuan tentang hal tersebut. 


\section{SOLUSI YANG DITAWARKAN}

Abad ke-21 merupakan era milenial, dimana generasi saat ini merupakan generasi yang highly mobile, apps-dependent dan selalu terhubung internet (internet connected). Khususnya generasi muda saat ini, mereka adalah self-learner yang selalu mencari sendiri pengetahuan yang mereka butuhkan dari berbagai sumber dan membagikannya kepada masyarakat. Oleh karena itu, dalam studi ini genarsi muda khususnya siswa Sekolah Menengah Atas ditargetkan memiliki pemahaman terkait jenis plastik berdasarkan kode resinnya untuk membangun generasi peduli lingkungan.

Untuk mewujudkan hal tersebut, telah dilakukan sosialisasi dan workhop pengenalan kode resin plastik pada Siswa SMA Tegar Kelana Desa Suranadi. Sebelum sosilasi dilakukan, siswa diminta mengisi quisioner untuk mengumpulkan data dan informasi terkait sejauh mana mereka mengenal dan menanggulangi sampah plastik di lingkungan mereka. Hal yang sama dilakukan setelah sosialisasi dan workshop dilakukan, untuk melihat respon siswa sebagai bahan evaluasi. Kegiatan ini dilakukan pada 21-23 agustus 2019, yang bertempat di sekolah SMA Tegar Kelana.

\section{HASIL DAN PEMBAHASAN}

Berdasarkan data yang diperoleh melalui kuisioner yang telah disebar terkait pengetahuan tentang plastik dikalangan siswa SMA Tegar Kelana Desa Suranadi menunjukan fakta-fakta yang umum terjadi di masyarakat yang ditampilkan pada Tabel 1. Dari seluruh siswa yang menjadi respondent menunjukan hanya $6.85 \%$ yang mengetahui bahan dasar plastik atau plastik terbuat dari apa, $91.85 \%$ tidak mengetahui bahan dasar plastik dan sisanya tidak yakin dengan pengetahuanya. Meskipun fakta ini umum terjadi di masyarakat, namun untuk kalangan siswa SMA tentu ini sangat memprihatinkan. Hal ini dikarenakan jenjang Pendidikan IPA dari tingkat sekolah dasar hingga tinggat sekolah lanjut seharusnya memberikan gambaran bahwa plastik terbuat dari fraksi minyak bumi.

\section{Tabel 1. Respon Siswa SMA Tegar Kelana Desa Suranadi terkait wawasan tentang plastik}

\begin{tabular}{llccc}
\hline \multicolumn{1}{c}{ Pertanyaan } & \multicolumn{3}{c}{ Respon (\%) } \\
\cline { 2 - 4 } & Ya & Tidak & Lainya \\
\hline 1. Apakah saudara tahu plastik terbuat dari & 6.85 & 91.42 & 1.73 \\
$\begin{array}{l}\text { apa? } \\
\text { 2. Apakah saudara tahu plastik terdapat }\end{array}$ & 74.38 & 18.42 & 7.20 \\
$\begin{array}{l}\text { dalam berbagai jenis? } \\
\text { 3. Apakah saudara sering memperhatikan }\end{array}$ & 30.20 & 23.54 & 46.26 \\
$\quad \begin{array}{l}\text { kemasan plastik yang saudara gunakan } \\
\text { sehari-hari? }\end{array}$ & 12.42 & 64.58 & 23.00 \\
4. Apakah saudar pernah melihat simbol & $\begin{array}{l}\text { Apgitiga anak panah pada plastik? } \\
\text { segand? }\end{array}$ & 7.45 & 85.52 & 7.03 \\
\hline
\end{tabular}

Selain pengetahuan tentang bahan dasar pastik, pengetahuan tentang jenis plastik yang sering kita temui juga masih sangat minim. Meskipun $74.38 \%$ responden mengaku mengetahui jenis-jenis plastik, namun pengetahuan yang dimiliki hanya sebatas dinilai dari fisik plastik tersebut misalkan plastik yang keras atau lunak, plastik tahan panas atau tidak, dan bahkan jenis plastik yang 
dapat dijual kembali atau tidak. Hal ini sedikit kontras dengan seberapa sering mereka memperhatikan jenis plastik yang mereka gunakan sendiri, karena hanya $30.20 \%$ responden yang mengaku selalu memperhatikan jenis plastik yang mereka gunakan. Sementara sebagian besar respondent (46.26\%) hanya kadang-kadang saja memperhatikan hal ini. Oleh karena itu, jenis plastik yang mereka amati bisa dikatakan hanya sebatas pengetahuan secara lisan atau diperoleh dari pengamatan sehari-hari dari tumpukan sampah.

Sedangkan pengetahuan tentang kode resin plastik dikalangan siswa SMA Tegar Kelana masih sangat minim. Dari data yang diperoleh hanya $12.42 \%$ dari responden yang mengaku selalu memperhatikan symbol kode resin plastik yang ada pada kemasan ataupun perabotan yang sering digunakan dalam kehidupan sehari-hari. Sementara $64.58 \%$ responden tidak pernah memperhatikan dan 23\% responden hanya melakukannya kadang-kadang. Sesuai dengan hipotesis yang diambil dalam penelitian ini, memang benar menunjukan hanya $7.45 \%$ mengetahui arti symbol kode resin pada plastik yang mereka amati. Padahal, kode resin plastik wajib dicatumkan oleh industry plastik untuk diketahui oleh masyarakat umum. Pengetahuan tentang kode resin plastik ini sangat penting untuk bisa menggunakan dan menangani plastik dengan benar sesuai dengan jenisnya.

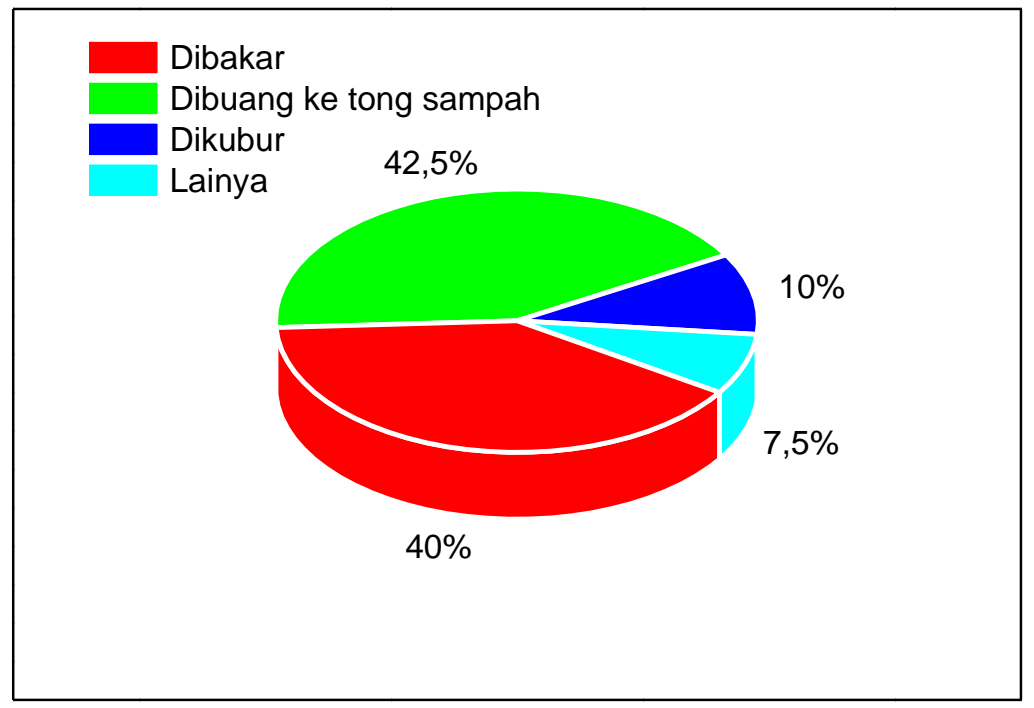

Gambar 1. Berbagai cara penangan sampah plastik siswa SMA Tegar Kelana Desa Suranadi

Sedangkan wawasan atau tindakan yang pernah mereka lakukan atau bahkan seringkali mereka lakukan dalam menanggulangi sampah plastik menunjukan fakta yang memang umum terjadi di masyarakat (Gambar 1). Dimana berdasarkan data yang diperoleh siswa SMA Tegar Kelana melakukan atau mengamati cara penangan sampah plastik dengan cara dibakar $(40.0 \%)$ dan dibuang ke tempat sampah saja (42.5\%). Sementara hanya $10.0 \%$ yang mengubur sampah plastik dikebun. Dari semua penangan yang dilakukan sesungguhnya masih sangat tepat. Kembali lagi, hal ini disebabkan kurangnya pemahaman terkait plastik itu sendiri. Penangan sampah plastik dengan cara dibakar akan melepaskan gas-gas beracun dari material plastik yang dapat mencemari lingkungan udara. Sementara teknik penguburan juga akan sangat tidak efektif dikarenakan sampah 
plastik sangat sulit terurai secara alami. Selain itu, penguburan sampah plastik dikebun juga dapat meningkatkan suhu tanah yang dapat memberikan dampah buruk pada akar tanaman atau pohon yang berada disekitarnya. Oleh karena perlu dukungan berbagai pihak baik masyarakat ataupun pemerintah untuk menanggulangi permasalahan ini, sehingga sampah plastik tidak hanya dibuang ketempat sampah dan dibawa ke tempat pembuangan akhir.

Terdapat banyak inovasi dan teknologi yang telah dikembangkan oleh para peneliti di Indonesia yang dapat diadopsi sebagai alernatif dalam penangan sampah plastik. Saat ini, banyak sekali hasil penelitian yang dilakukan dalam mengkonversi sampah plastik menjadi barang atau bahan bernilai ekonomi. Minyalnya mengkonversi sampah plastik yang tidak dapat didaur ulang menjadi bahan bakar cair, material bangunan atau bahkan wax. Hal yang harus diperhatikan dalam berinovasi dengan sampah plastik adalah konversi yang dilakukan harus berbasis zero waste atau habis pakai. Selain itu, konversi yang dilakukan juga disarankan kearah material yang digunakan secara permanen.
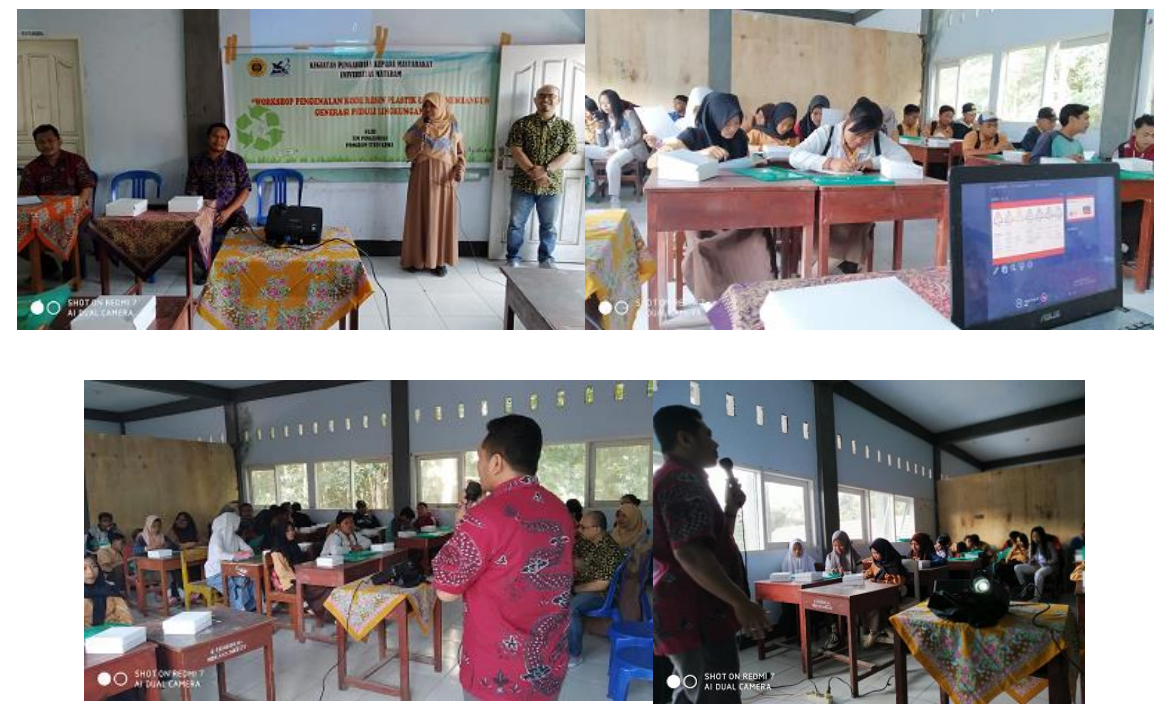

Gambar 2. Sosialisasi Pengenalan Kode Resin Plastik di SMA Tegar Kelana Desa Suranadi

Dari hipotesis dan data yang diperoleh prasosialisasi inilah yang mendorong kami untuk melakukan sosialisasi. Siswa-siswa SMA Tegar Kelana sangat antusias mendengarkan sosialisasi yang diberikan. Terlihat pula bahwa materi yang diberikan memang benar-benar asing dimata mereka. Sosialisasi dilakukan dengan mengenalkan simbol-simbol kode resin plastik yang umum dijumpai dalam kehidupan sehari-hari (Gambar 3.) (Seaman, 2012). 


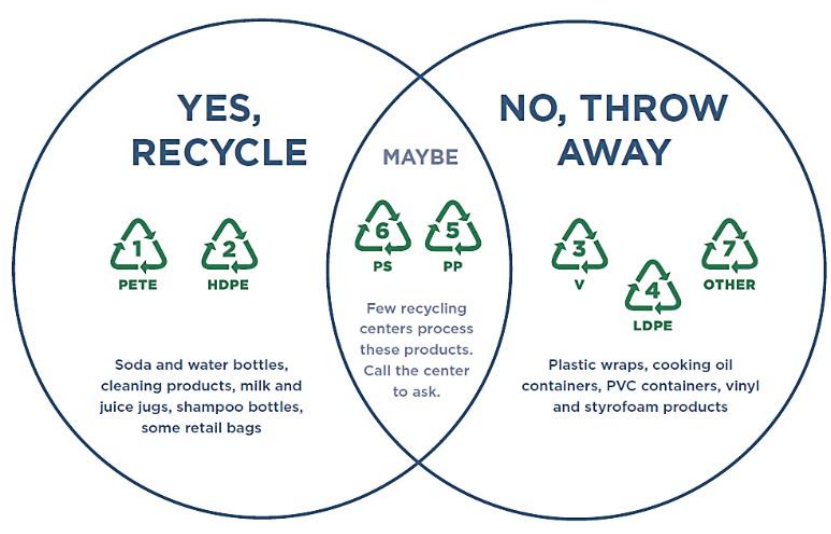

Gambar 3. Logo plastik berdasarkan RIN dan kemungkinan untuk didaurulang

Selain itu, sosialisasi juga dibarengi dengan praktek langsung dengan mengidentifikasi jenis plastik yang ada disekitarnya mulai dari pembukus jajan, botol air mineral dan sebagainya.Sebagai bahan evaluasi, quisioner juga disebar untuk melihat respon setelah mengikuti kegiatan. Evaluasi yang dilakukan dengan mengidentifikasi simbol kode resin plastik. Dari data yang diperoleh menunjukan $84.55 \%$ telah melakukan identifikasi jenis plastik berdasarkan nomor kode resin plastik baik yang tertera ataupun tidak tertera pada badan plastik. Selain itu, respon yang perlu diperhatikan dan sebagai bahan pertimbangan adalah terkait keberlanjutan kegiatan (Tabel.2).

Tabel. Respon Siswa SMA Tegar Kelana setelah mengikuti kegiatan sosialisasi.

\begin{tabular}{llcc}
\hline \multicolumn{1}{c}{ Pertanyaan } & \multicolumn{3}{c}{ Respon (\%) } \\
\cline { 2 - 4 } & Ya & Tidak & Lainya \\
\hline 1. Apakah sosialisasi ini menambah & 98.04 & 0.00 & 1.96 \\
$\begin{array}{l}\text { pengetahuan saudara? } \\
\text { 2. Apakah sudah ada ide tindak lanjut? }\end{array}$ & 75.45 & 23.42 & 2.20 \\
3. Apakah saudara membutuhkan & 84.95 & 0.00 & 15.05 \\
$\begin{array}{l}\text { kegiatan lebih serupa lebih lanjut? } \\
\text { 4. Apakah saudara bersedia meneruskan } \\
\text { informasi ini? }\end{array}$ & 85.64 & 0.00 & 14.36 \\
\hline
\end{tabular}

Dari data respon akhir yang diperoleh menunjukan keberhasilan kegiatan yang diharapkan. Dimana $98.04 \%$ merasa mendapat pengentahuan yang bermanfaat terkait plastik. Selain itu, ide tidak lanjutnya dari beberapa siswa juga sangat beragam, diantaranya ada siswa yang ingin menggalakan kembali karang taruna dilingkungan mereka, ada juga siswi yang ingin memilah jenis plastik yang baik digunakan sebagai perabotan rumah tangga. Meski demikian, ini hanyalah kegiatan pada system yang sangat kecil. Sehingga peru adanya kegiatan lebih lanjut dengan sekala yang lebih besar dan melibatkan pemerintah khususnya pemerintah daerah NTB yang sedang menggalakan program zero waste. Karena program tersebut tidak berhasil secara permanen jika hanya dilakukan secara fisik saja, tanpa dibarengi dengan edukasi masyarakat. 


\section{KESIMPULAN}

Dari kegiatan yang telah dilakukan dapat disimpulkan bahwa, untuk menumbuhkan generasi peduli lingungan dapat melalui edukasi pada siswa-siswi sekolah sebagai agent perubahan. Karena berdasarkan fakta yang diperoleh dilapangan, pengetahuan tentang plastik di masyarakat masih sangat minim. Minimnya pemahaman ini berdapak pada pola piker masyarakat yang kurang bijak dalam menggunakan dan menanggulangi sampah plastik. Edukasi pada masyarakt, dapat dimulai dari siswa-siswi sekolah yang nanti akan membawa pengaruh ke masyarakat umum dalam menyikapi penggunaan dan penanggulangan sampah plastik berdasarkan kode resinnya.

\section{UCAPAN TERIMA KASIH}

Ucapan terima kasih kami sampaikan kepada Universitas Mataram Khususnya Lembaga Penelitian dan Pengabdian Kepada Masyarakat yang telah mendukung kegiatan ini dan Fakultas MIPA Universitas Mataram melalui dana PNBP yang telah diberikan.

\section{REFERENSI}

Insidelombok. (2019, Juni 29). 2.695 Ton Sampah NTB Belum Terurus. Retrieved from Insidelombok: https://insidelombok.id/uncategorized/2-695-ton-sampah-di-ntb-tak-terurus/

J.R. Jambeck, R. G. (2015). Plastic Waste Input From Land into The Ocean. Beijing: Scinecemag.org.

LeChevet, C., Larrivee, R., Ergastolo, M., \& Robledo, L. (2018). Earth Day 2018 -Plastic Pollution Primer and Action Toolkit. Earth Day Network.

Merino, V., Ayer, D., LeChevet, C., Larrivee, R., Ergastolo, M., \& Robledo, L. (2018). Plastic Pollution Primer and Action Toolkit. Earth Day Network.

Redaksi ACTNews . (2018, Juni 9). Senja Ramadan di Bukit Sampah TPA Kebon Kongok. Retrieved from ACTNEWS: https://news.act.id/berita/senja-ramadan-di-bukit-sampah-tpa-kebon-kongok

Seaman, G. (2012, May 2). Plastics by the number. Retrieved Desember 20, 2018, from Eartheasy: https://learn.eartheasy.com/articles/plastics-by-the-numbers/ 